\title{
O modelo sociológico revisitado no documentário político Encontro com Milton Santos. O mundo global visto do lado de cá
}

María Celina Ibazeta

\section{Resumo:}

Este artigo se propõe a trabalhar com o documentário de Silvio Tendler Encontro com Milton Santos. O mundo global visto do lado de cá (2006), analisando a coerência entre sua proposta temática (a defesa dos direitos dos setores populares) e sua forma. Para isso, considero fundamental a concepção do modelo sociológico de JeanClaude Bernardet. As categorias elaboradas por Bernardet continuam vigentes para revisar as complexas relações entre poder e imagem no discurso do documentário político.

\section{Palavras Chave:}

Documentário político, documentário brasileiro contemporâneo, modelo sociológico.

\begin{abstract}
:
This article analyses the cohesion between thematic proposals (the defense of popular sector's rights) and formal strategies in the Brazilian documentary Encontro com Milton Santos. O mundo global visto do lado de cá (2006), by Silvio Tendler. In this way, we consider Jean-Claude Bernardet's sociological model, whose categories are still valid to criticize the complex relations among the power and the images in political documentaries discourses.
\end{abstract}

Keywords:

Political documentary, Brazilian contemporary documentary, sociological model.

Podemos dizer que o documentário latino-americano político surge na década de 60 . O contexto revolucionário da época foi o caldo de cultura que estimulou os documentaristas a fazer filmes que levassem o público a refletir sobre a realidade política e social. A crença quase absoluta de que o cinema era um arma política eficaz de mudança do sistema social radicalizou cada vez mais a atividade cinematográfica. Filmar se tornou progressivamente uma militância.

A linguagem do documentário engajado no mundo social adotou o modo expositivo tal como é enunciado por Bill Nichols. Esse modo, conhecido também como clássico, apresenta o mundo histórico de forma retórica ou argumentativa. A voz over tem uma forte presença e constrói o argumento do filme, ajudando a criar uma impressão de objetividade e credibilidade sustentadas em sua distância e sua onisciência. As citações, entrevistas e imagens estão subordinadas a uma lógica textual que apresenta uma perspectiva determinada do mundo social e procura o apelo do espectador (NICHOLS, 2005: 142-146).

O documentário contemporâneo se afastou muito do modo expositivo. Desde a década de 80 até o momento, observa-se uma forte tendência para a exaltação da subjetividade individual. A voz over desapareceu quase totalmente e deu espaço para a voz das personagens. É através da sua perspectiva que o argumento do filme se constrói. O documentário não tem a pretensão de ser um produto acabado, um ensaio completo e coerente pronto a informar ou mobilizar seu público. Pelo contrário, concebe-se como um processo que tenta se vincular com o espectador pela afetividade e não pela racionalidade. O público acompanha o realizador no processo de realização do filme e no desenvolvimento de sua relação com os entrevistados. A própia história pessoal do realizador torna-se, por vezes, parte do filme. Uma perspectiva anteriormente mais engajada politicamente dá 
lugar a um olhar mais intimista. A denúncia e a crítica social, se existirem, encontram-se em um espaço doméstico.

Em 2006 o diretor brasileiro Silvio Tendler apresentou Encontro com Milton Santos. O mundo global visto do lado de cá, que vai na contracorrente da produção atual. Esse documentário, que traz de volta o modo expositivo (1), faz uma crítica às políticas governamentais que causaram profundas crises na sociedade civil, conseqüência da implantação do neoliberalismo na América Latina. A mídia, visual e escrita, é desprestigiada por apoiar a política econômica dos grupos dominantes. O filme dá visibilidade à resistência social: manifestações, passeatas e protestos diversos invadem a tela. Um olhar esperançoso expõe de modo geral os movimentos sociais contra as políticas da globalização e o trabalho de cineastas engajados que acompanham essas lutas com sua câmera.

Dada a indiscutível postura contra-hegemônica desse filme, este trabalho se propõe a revisar a coerência entre suas propostas de defesa dos direitos dos pobres e dos excluídos e sua maneira de apresentar seus depoimentos. Para isso, considero fundamental a concepção do modelo sociológico de Jean-Claude Bernardet. É a partir de seus aportes que se desenvolve a análise do filme de Tendler.

Jean-Claude Bernardet, em seu livro Cineastas e imagens do povo, analisa documentários brasileiros dos anos sessenta que tratam do que ele chamou "modelo sociológico". Esses documentários têm como ponto de partida um aparato conceitual que organiza o real. Os filmes partem de pesquisas sociológicas cujas conclusões são ilustradas ao longo do processo de filmagem através da amostragem de entrevistas. A esse mecanismo ele chamou sistema de informação geral/particular.

Bernardet aponta categorias-chave para avaliar a informação. Ele distingue diferentes vozes que estabelecem uma hierarquia bem definida. Utilizando como objeto de estudo o filme Viramundo (1964) de Geraldo Sarno, Bernardet caracteriza a voz do povo como a voz da experiência: "Falam só de suas vivências, nunca generalizam, nunca tiram conclusões. Ou porque não sabem, ou porque não querem, ou porque nada lhes é perguntado nesse sentido" (BERNARDET, 2003: 16). Em Viramundo, a voz do saber é a voz do locutor, às vezes a voz over, outras vezes a voz do entrevistador:

Diferentemente dos entrevistados, nada lhe é perguntado, fala espontaneamente e nunca de si, mas dos outros, dos migrantes, não apenas dos entrevistados, mas dos migrantes em geral que vieram para São Paulo (...) O locutor não fala como eles. Eles falam de si na primeira pessoa, ele fala deles na terceira; enquanto os migrantes falam de suas situações particulares, ele fala deles em um plano geral (BERNARDET, 2003: 16-17).

Por vezes, mesmo a voz de um dos entrevistados assume um papel de intermediário entre a voz do locutor e a voz da experiência, ajudando o locutor a expressar suas idéias e conceitos. Bernardet chama de locutor auxiliar a esses intermediários que falam dos entrevistados de modo geral e assumem una posição de poder no sistema de informação, status que também exercem na vida real. Estabelece-se assim uma relação sujeito (do saber)/objeto (do saber).

Em Viramundo existe uma tensão entre a postura ideológica e política e a atitude sociológica do realizador. Se por um lado ele está do lado dos oprimidos e simpatiza com eles durante todo o filme, por outro lado, no sistema de informação a voz privilegiada é a do empresário e não a dos operários. Paradoxalmente, o interesse desses filmes pela realidade das classes populares está em contradição com seu desprezo por sua capacidade explicativa e reflexiva. Bernardet apresenta a reprodução da desigualdade da estrutura social no documentário. Mesmo na procura de transformação, o documentário reproduz a hierarquia social contra a qual muita vezes diz lutar contra. 
O sociólogo Pierre Bourdieu chama de capital simbólico aquilo que é considerado valioso numa sociedade e que está legitimado pelas instituções (Bourdieu, 1990: 154). Nesse sentido, os documentários que seguem o modelo sociológico desnudam a divisão hierárquica entre o saber da classe baixa, operários ou camponeses, que é ignorado, e o saber acadêmico das classes média e alta, que tem lugar de prestígio no filme. Essa distinção arbitrária mas natural no mundo social se reflete nos filmes.

\section{Nosso encontro com o pensamento de Milton Santos}

O documentário Encontro com Milton Santos. O mundo global visto do lado de cá surgiu do interesse de Tendler (2) pelo pensamento crítico de Milton Santos sobre a globalização. Santos fora entrevistado pelo realizador para o filme Josué de Castro, cidadão do mundo. A entrevista de uma hora e meia, a última de Santos antes de falecer em 2001, teve lugar na Universidade de São Paulo (USP) e é o material-chave do filme. Tendler escolheu Santos como o locutor do documentário e seu trabalho e de sua equipe foi fornecer casos concretos da realidade para exemplificar suas idéias. O filme, em palavras do própio Tendler, tem uma estrutura de quebra-cabeça. Ele se compõe de material de arquivo de televisão; partes de um outro filme de Tendler, Utopia e barbárie; trechos de outros filmes, como The corporation (2003), de Mark Ackbar e Jennifer Abbot, Thirst (2004), de Alan Snitow e Deborah Kaufman, e Dia de festa (2005), de Toni Venturi e Pablo Georgieff; entrevistas feitas especialmente para o filme; citações de escritores críticos como Jean Paul Sartre, Fanz Fanon e Josué de Castro; e animação gráfica. Essa colagem nos lembra o cinema urgente do cubano Santiago Álvarez, cujo discurso político se constrói com base em um intenso e criativo uso da montagem de diversos materiais imagéticos e sonoros (LABAKI, 1994: 11).

O nome do documentário alude a uma conversa ou a um diálogo. Entretanto, há poucas perguntas, três ou quatro, exclusivamente no início e no final. A voz de Tendler, a quem não vemos, desaparece completamente no restante do filme. O diálogo vira depoimento, e a figura de Santos domina o filme. A voz over e os cartazes que lemos são muitas vezes citações do livro de Santos Por uma outra globalização. Do pensamento único à consciencia universal (2000). Vários dos trechos selecionados das entrevistas e das palestras de Santos têm estreita relação com o pensamento de seu livro. No início vemos Santos escrever uma dedicatória para o diretor. O livro é parte do encontro e também do filme. O pensamento do locutor está legitimado assim pela palavra escrita, o que dá força e autoridade a seu depoimento.

A escolha de um intelectual negro do terceiro mundo que se diz um "marxista marxizante" crítico da globalização atual é uma aposta original, em tempos em que o pensamento de esquerda e a figura do intelectual ficaram enfraquecidas pela queda do comunismo, pelas ditaduras e seu terror de estado. A figura do intelectual reaparece no documentário, mas em uma posição muito diferente. Santos não é, nem pretende ser, o dono absoluto da verdade que ensina/conscientiza aos outros. Pelo contrário, diz confiar plenamente na lucidez, na experiência e na força dos setores populares para construir uma outra globalização. Ele dirige nosso olhar à realidade, às organizações e às pessoas que lutam por mudanças há bastante tempo. Sílvio Tendler admite ter aprendido muito de Milton Santos. Foi justamente através dele que Tendler descobriu as pessoas que aparecem no seu documentário.

O livro de Santos pode ser dividido, como ele mesmo explica no prefácio, em uma descrição de como é a realidade e uma descrição de uma possível realidade futura. O filme se estrutura da mesma forma. Na primeira parte, utiliza-se uma montagem de evidência para construir o conceito de globalização como fábula e como perversidade e para criticar a mídia e sua aliança com os grupos de poder. Mas, ao contrário do livro, que não dá exemplos pontuais e concretos da realidade, o filme mostra as conseqüências dos efeitos negativos da globalização nas múltiplas revoltas na América do Sul e no mundo contra a política das privatizações. A segunda parte argumenta como o uso da tecnologia pode criar uma rede de informação dos movimentos populares para dar conta de suas lutas e sua cultura. Nesse caso todos os exemplos de cineastas engajados com as classes populares são brasileiros. 
A primeira impressão é que a estrutura do modelo sociológico se reproduz no filme de Tendler. Por uma parte sim e por outra não. A clássica figura do intelectual ocupa o lugar da voz de saber que explica o funcionamento da globalização na atualidade e vislumbra um possível caminho futuro de uma globalização mais solidária. A utilização do pensamento de Santos expresso por ele mesmo e por uma voz over como o fio condutor do filme é uma forma de lhe render uma homenagem e de impor um olhar descolonizador, produzido no terceiro mundo. Para sustentar as idéias de Santos, o filme incorpora uma grande quantidade de depoimentos, alguns feitos para o filme e outros incorporados como material de arquivo. Esse amplo conjunto reproduz o sistema geral/particular de Bernardet. A teoria abstrata elaborada pelo sujeito do saber é confirmada por uma amostragem.

Apesar disso, os novos personagens que aparecem no filme obrigam a repensar as categorias existentes, criar novas e refletir sobre seu funcionamiento na obra. Esse é o caso do grande grupo de cineastas que dão seu depoimento no filme e são pouco ou nada conhecidos no meio artístico e os novos grupos emergentes, muito diferentes dos grupos que representavam o "povo" na década de sessenta.

Um grupo de cineastas e video-makers fala da sua prática cinematográfica envolvida com o ativismo e a cultura popular. Seu papel é o de difundir na sociedade o discurso dos grupos não hegemônicos. Eles também falam das comunidades com as quais trabalham, tanto através do discurso verbal como do discurso da imagem. Seu trabalho nasce do forte contato com a experiência militante dos grupos populares, em que a maioria deles está inserida. Esta voz não é a voz do locutor auxiliar nem a voz da experiência. Para distingui-los os chamarei voz do mediador: quase nenhum pertence ao universo em que filmam, todos são de classe média e o sujeito filmado por eles é um outro de classe. A única exceção no filme é Ailton Krenak, que é indígena e trabalha com comunidades indígenas. Todos eles usam a imagem como uma ferramenta para fortelecer a identidade da comunidade em questão e para fornecer um contradiscurso na sociedade. Por isso, é fundamental para eles falar de seu trabalho com a câmera. Ela é o vínculo que os une com os grupos populares: Carlos Pronsato filma os funcionários das fábricas recuperadas na Argentina e manifestantes bolivianos em La Paz; Ailton Krenak e Joaquín Yawanawa, líderes e cineastas indígenas, trabalham com a comunidade indígena Krenak; Adirley Queiroz se interessa pelos rappers da Ceilândia; Aline Sasahara acompanha o Movimento Sem Terra; e Pablo Cunha faz cinema em Japeri, em uma comunidade pobre do subúrbio de Rio de Janeiro.

Encontro com Milton Santos é um documentário que constrói uma imagem muito positiva do povo. Lucidez, organização e determinação são algumas das características que descrevem as classes populares. A fala do locutor e dos locutores auxiliares se materializa nas ações concretas das massas. São os próprios atores sociais os que se expressam ante as câmeras com plena consciência de seus direitos e das injustiças contra as quais lutam. O povo não é mais retratado como uma massa alienada, assim como o intelectual não é mais essa figura messiânica que deve conscientizar a multidão. Vemos os intelectuais e os grupos populares dizendo as mesmas coisas.

Essa nova imagem do povo surge ao longo das entrevistas nas quais as pessoas fazem generalizações, críticas e denúncias. Os entrevistados não falam de uma experiência individual, mas sim coletiva; em sua maioria são parte de um movimento social; falam sozinhos para a câmera, porém em nome de um "nós". Esses entrevistados são sujeitos, são atores sociais, agentes na terminología de Anthony Giddens (1995: 43-51). A essas entrevistas as chamarei voz da experiência mobilizada, já que possuem um saber que vem da experiência de grupos de base e não do discurso.

\section{O poder da fala e de quem fala}

A hierarquia que há entre os depoimentos se estabelece pela irregular distribução do sistema de informação. A informação sobre cada entrevistado no depoimento que registra os créditos não é a mesma para todos, nem sempre temos acesso aos dados de todos os entrevistados. A total falta de um critério uniforme sobre o formato 
dos créditos do filme instala a suspeita de que cada fala tem um valor diferente. Agrupamos os depoimentos de acordo com sua visibilidade. Os primeiros lugares correspondem às pessoas sobre as quais temos mais informação, e os últimos, aos depoimentos sobre os quais temos menos ou nehuma informação.

Em primeiro lugar encontramos a voz dos mediadores. Todos eles são apresentados pela voz over e pelos créditos, que especifícam nome e profissão, quase todos cineastas. Estão duplamente nomeados, pelo registro oral e escrito. Em segundo lugar estão os locutores auxiliares (3), cujos créditos os identificam e informam-nos sobre seus cargos, chegando a informar mesmo sobre prêmios recebidos, como o Nobel. Em último lugar estão as vozes da experiência mobilizada (4). Em alguns casos os entrevistados são identificados com créditos que dão o nome e sobrenome das pessoas, ou somente o nome e um dado pessoal, ou um dado vinculado a sua atuação no momento da entrevista. Em outros, sem nehum motivo aparente, não são identificados.

A falta de uma norma consistente é muito visível na voz da experiência mobilizada. No caso da Bolívia, Sergio Queiroz é um homem que pede a industrialização e nacionalização dos hidrocarbonetos, e é apresentado como um morador de El Alto. Esse fato é importante. Os moradores desse bairro têm um elevado grau de organização e intervenção social. Em sua fala, o entrevistado se refere a seu bairro quando diz: "Nós temos um lema: o Alto de pé, nunca de joelhos". Ou seja, saber de onde o entrevistado vem é importante nesse caso. A próxima entrevistada, que não vem acompanhada dos créditos, diz que os bolivianos deveriam ter gás garantido a preços mais baixos. No caso da Argentina encontramos dois manifestantes, sendo que somente um deles é identificado como "Argélia, manifestante". O outro entrevistado também parece estar numa manifestação, se não a mesma, mas nada é dito sobre ele. Em uma entrevista feita no Rio de Janeiro, os dois integrantes afetados do movimento sem teto, que dão excelentes argumentos contra a expulsão de moradores de prédios ocupados ilegalmente, não são identificados.

É obvio que o realizador valoriza esses depoimentos, já que os incorpora como material do documentário. De fato os depoimentos são os mais interessantes porque desarticulam a idéia de que o povo não tem consciência política e está desinteressado pelo rumo da nação. O diretor Silvio Tendler lembrou inclusive com carinho desses dois depoimentos dos sem teto em uma entrevista sobre o filme realizada para esta pesquisa, dizendo que "eles têm uma bela consciência social".

Como explicar essa divergência no sistema de informação? Divergência no que é falado sobre as pessoas e divergência na aparição ou não dessa informação. Nossa hipótese é que a ênfase na informação sobre os cineastas, que consta como primeiro grupo, se explica pela maior identificação do diretor e sua equipe com eles. O fácil acesso à informação de pessoas prestigiosas (e não ao geral da população) e a valorização do saber intelectual parecem ser as causas do irregular sistema de informação.

\section{Conclusões}

Encontro com Milton Santos é um documentário singular. Diferentemente dos documentários atuais que trabalham com a subjetividade, a história pessoal e o espaço doméstico, Tendler escolhe voltar a uma reflexão político-social provocadora. Com exemplos do mundo inteiro, o documentário mostra as consequiências negativas da globalização através das revoltas populares. Se na década de sessenta o documentário político e militante procurava motivar a organização e mobilização do povo, no novo milênio a câmera sai às ruas para registrar esses fatos.

Tendler mostra uma nova imagem dos setores populares, mas sem inovar na sua forma. A reprodução de uma hierarquia nas vozes das testemunhas é acentuada pelo arbitrário e inconsistente sistema de informação. Esse tratamento desigual dos depoimentos entra em contradição com a boa intenção do diretor e do documentário de fazer do mundo um espaço mais democrático. É claro que o problema do documentário político é ainda a adoção de uma forma mais compatível com seu conteúdo. 


\section{Bibliografia:}

BERNARDET, Jean-Claude. Cineastas e imagens do povo. São Paulo: Companhia das Letras, 2003.

BOURDIEU, Pierre. As coisas ditas. São Paulo: Brasiliense, 1990.

GALVÃO, Rita \& BERNARDET, Jean-Claude. O Nacional e o popular na cultura brasileira. Rio de Janeiro: Brasiliense, 1983.

GIDDENS, Anthony. La constitución de la sociedad. Buenos Aires: Amorrortu, 1995.

LABAKI, Amir. Introdução ao documentário brasileiro contemporâneo. São Paulo: Francis, 2006.

LINS, Consuelo \& MESQUITA, Claudia. Filmar o real. Sobre o documentário brasileiro contemporâneo. Rio de Janeiro: Jorge Zahar, 2008.

NICHOLS, Bill. La representación de la realidad. Cuestiones y conceptos sobre el documental. Madrid: Paidos, 1997.

. Introdução ao documentário. Campinas: Papirus, 2005.

XAVIER, Ismael. Cinema brasileiro moderno. São Paulo: Paz e Terra, 2001.

\section{Notas:}

Trabalho realizado com apoio do CNPq.

(1) Entre os documentários contemporâneos que utilizam o modo expositivo podem mencionar-se: Memoria del saqueo (2004) e Argentina Latente (2007), de Fernando Ezequiel Solanas, Romper el cerco, (2006) de Mario Viveros e Nicolás Défossé, e Ojos bien abiertos (2007), de Gonzalo Arijon.

(2) Todas as informações citadas provêm de uma entrevista com Sílvio Tendler realizada por mim em 2008.

(3) Os locutores auxiliares que encontramos no filme são: Joseph Stiglitz, prêmio Nobel de Economia, Celso Amorim, ministro de relações exteriores, Charles Kernaghan, diretor do comitê de trabalho americano, intelectuais reconhecidos, como José Saramago, Eduardo Galeano, Adetokunbo Borishade e Boubacar Boris Diop.

(4) As vozes da experiência são muito poucas e têm o mesmo problema da arbitrariedade do sistema de informação: às vezes aparece o nome e a profissão; noutras, o nome e a idade.

\section{Mini Currículo :}

Doutora pela State University of New York (SUNY) at Stony Brook, sob orientação de Kathleen Vernon. Mestrado em literatura hispânica e bacharelado em letras pela Facultad de Filosofía y Letras (Universidad Nacional de Tucumán, Argentina). Especialização em literatura e cinema latino-americano contemporâneo. 